\title{
MELHORES PRÁTICAS DE ENFERMAGEM: POTENCIALIDADES E DESAFIOS EM UM CONTEXTO ASSISTENCIAL
}

\section{BEST NURSING PRACTICES: POTENTIALS AND CHALLENGES IN AN ASSISTENTIAL CONTEXT}

\section{MEJORES PRÁCTICAS DE ENFERMERÍA: POTENCIALES Y DESAFÍOS EN UN CONTEXTO DE ASISTENCIA}

\author{
Mônica Ludwig Weber ${ }^{1}$, Carine Vendruscolo ${ }^{2}$, Edlamar Kátia Adamy ${ }^{3}$, Letícia de Lima Trindade ${ }^{4}$, Ivonete Teresinha Schulter Buss \\ Heidemann ${ }^{5}$, Daisi Rosset ${ }^{6}$
}

\section{RESUMO}

Objetivo: compreender as potencialidades e desafios no desenvolvimento de melhores práticas de enfermagem em um contexto assistencial. Método: estudo qualitativo, pautado no referencial metodológico de Paulo Freire, a partir das etapas: investigação temática, codificação e decodificação e desvelamento crítico, realizado por meio de três Círculos de Cultura. Participaram 17 enfermeiros atuantes em serviços de atenção primária, secundária e terciária, em três municípios, entre os meses de junho a agosto de 2018. Resultados: apesar dos inúmeros desafios que envolvem as práticas, como a falta de diálogo entre enfermeiros e com equipe multiprofissional, além da pouca familiaridade com as dimensões (tríade) das melhores práticas, destacaram-se como potencialidades: a liderança da enfermagem, o vínculo com o usuário, entre outros. Conclusão: os enfermeiros buscam aprimorar suas práticas naquele contexto, contudo, faz-se necessário estabelecer a comunicação entre eles em espaços dialógicos, que despertem a avidez pela busca e compartilhamento do saber, na direção das melhores práticas. Com o uso de metodologias críticoreflexivas como os Círculos de Cultura comprovou-se uma oportunidade para a problematização do processo de trabalho, podendo contribuir para o diálogo e a reflexão.

Descritores: Serviços de Saúde; Enfermagem; Assistência Integral à Saúde; Padrões de Prática em Enfermagem.

\section{ABSTRACT}

Objective: To understand the potentialities and challenges in the development of best nursing practices in a care context. Method: qualitative study, based on Paulo Freire's methodological framework, with the following steps: thematic research, coding and decoding and critical unveiling in three Culture Circles. Seventeen nurses working in the Health Care Network involving three municipalities, from June to August 2018 participated in the study. Results: Despite the numerous challenges involving the practices, such as the lack of dialogue between nurses and the multidisciplinary team, as well as the lack of familiarity with the dimensions (triad) of best practices, the following stand out as potentialities: nursing leadership, the link with user, among others. Conclusion: nurses seek to improve their practices in the Network, however, it is necessary to establish communication between them, in dialogic spaces that arouse the eagerness to seek and share knowledge, towards the best practices. The use of criticalreflexive methodologies such as the Culture Circles proved an opportunity for problematizing the work process and could contribute to dialogue and reflection.

Descriptors: Health Services; Nursing; Comprehensive Health Care; Practice Patterns, Nurses.

\section{RESUMEN}

Objetivo: Comprender los potenciales y desafios en el desarrollo de las mejores prácticas de enfermería en un contexto asistencial. Método: Estudio cualitativo, fundamentado en el marco metodológico de Paulo Freire, basado en los siguientes pasos: investigación temática, codificación y decodificación y presentación crítica entre círculos culturales. Diecisiete enfermeras que trabajan en la red de atención médica en tres municipios, de junio a agosto de 2018, participaron en el estudio. Resultados: A pesar de los numerosos desafíos que implican prácticas, como la falta de diálogo entre las enfermeras y el equipo multidisciplinario, así como la falta de familiaridad con las dimensiones (tríada) de las mejores prácticas, las siguientes destacan como potencialidades: liderazgo de enfermería y el vínculo con el usuario, entre otros. Conclusión: las enfermeras buscan mejorar sus prácticas en la red asistencial, sin embargo, es necesario establecer comunicación entre ellas, en espacios dialógicos que susciten el afán de buscar y compartir conocimientos, hacia las mejores prácticas. El uso de metodologías crítico-reflexivas, como los Círculos de Cultura, brindan una oportunidad para problematizar el proceso de trabajo y podría contribuir al diálogo y la reflexión. Descriptores: Servicios de Salud; Enfermería; Atención integral de Salud; Pautas de la Práctica en Enfermería.

${ }^{1}$ Mestranda em Enfermagem pela Universidade do Estado de Santa Catarina. ${ }^{2}$ Doutora em Enfermagem. Docente do Programa de Mestrado Profissional em Enfermagem na Atenção Primária à Saúde da Universidade do Estado de Santa Catarina. ${ }^{5}$ Doutora em Enfermagem. Docente do Departamento de Enfermagem e do Programa de Pósgraduação em Enfermagem (Mestrado e Doutorado) da Universidade Federal de Santa Catarina. ${ }^{6}$ Enfermeira Coordenadora de cuidados paliativos domiciliares e comunitários.

Como citar este artigo:

Weber ML, Vendruscolo C, Adamy EK, et al Melhores p'raticas em enfermagem na rede de atneção à saúde: potencialidades e desafios. 2019;9:e3504. [Access ]: Available in: DOI: http://dx doi.org/10.19175/recom v9i0.3504 


\section{INTRODUÇÃO}

O modelo de atenção à saúde, assim como os serviços e os profissionais, necessita acompanhar a evolução da informação e rever a qualidade da assistência prestada. Soma-se a isso, o momento de crise, cujas pressões que recaem sobre o Sistema Único de Saúde (SUS), (re) definem a saúde como objeto de troca e competição entre o setor público e privado, convertendo à mera mercadoria essa valiosa dimensão da vida ${ }^{(1)}$. Convém destacar ainda, nesse contexto, as mudanças no perfil sociodemográfico brasileiro, em especial o aumento da expectativa de vida da população e a crescente taxa de doenças crônicas não transmissíveis.

Nesse horizonte desafiador, arranjos organizacionais, na saúde pública, compreendem serviços de diferentes densidades tecnológicas e ações que se interligam de modo a intervir no processo saúde-doença, observando os princípios do $\operatorname{SUS}^{(2-3)}$ e favorecendo a criação de vínculos entre profissionais, usuários e organizações, com redução de custos, aprendizagem mútua e fortalecimento da sinergia entre o conhecimento e as ações de melhoria na qualidade da assistência ${ }^{(4)}$. Ganha destaque, nessa perspectiva, a estruturação do Sistema a partir da Atenção Primária à Saúde (APS) - também Atenção Básica $(A B)$, no Brasil -ordenadora da Rede de Atenção à Saúde(RAS) e via preferencial de acesso para os usuários. Contudo, permanecem obstáculos como a falta de conscientização dos gestores e das equipes de saúde quanto à relevância desse modelo organizativo e o desconhecimento dos profissionais sobre as possibilidades de gerir os serviços ${ }^{(5)}$.

Em relação à atuação dos profissionais no âmbito do SUS, a do enfermeiro é considerada fundamental para a condução e articulação da assistência, pois trata-se de um facilitador na interligação entre os diferentes níveis assistenciais, principalmente, por sua proximidade com o usuário e com a comunidade, suas habilidades para dialogar com os demais profissionais da equipe de saúde e seu conhecimento do território ${ }^{(6)}$. Tais habilidades evoluem com a experiência profissional e se aprimoram mais, atualmente, com a busca e utilização de evidências científicas na prática de enfermagem, pois pautar a conduta profissional em tradições, conselhos de colegas e/ou manuais desatualizados não é mais tolerado, pelo contrário, se faz necessário potencializar a assistência ética e respeitosa, garantindo a segurança do usuário no serviço de saúde ${ }^{(7)}$. Observado o contexto, identificam-se lacunas que interferem diretamente, no exercício profissional do enfermeiro, a saber: a falta de domínio de novas tecnologias de gestão do cuidado e déficits referentes à formação, na qual se percebe a fragilidade em problematizar o saber e o fazer profissional, à luz de referências conceituais e metodológicos que promovam a criticidade e a autonomia ${ }^{(8)}$. Os processos de formação de pessoal para atuar no SUS, embora este seja o maior empregador do setor saúde no Brasil, permanecem direcionados às demandas de mercado, de encontro às reais necessidades de mudanças e fortalecimento da APS. As instituições formadoras apresentam propostas que fortalecem a incorporação do ensino tecnológico de alta complexidade, a custos elevados, destacando-se as especialidades ${ }^{(9)}$.

Acredita-se no resgate das melhores práticas de enfermagem como possibilidade de atender e fortalecer os princípios da APS, e, consequentemente, do SUS. Considera-se uma "melhor prática" aquela definida como técnica ou metodologia que, pela experiência ou investigação, possui confiabilidade comprovada para produzir um bom resultado. Em outras palavras, consiste no conhecimento sobre a prática que funciona em situações e contextos específicos, com a utilização racionada de recursos para atingir os resultados desejados, e que pode ser replicada em outras situações ou contextos $^{(10)}$. A Melhor Prática é formada, portanto, por uma tríade: experiência(1), investigação(2), confiabilidade, considerando as necessidades de cada usuário/pessoa e o menor custo(3) $)^{(10)}$.

No contexto dos serviços de saúde, as melhores práticas de enfermagem perpassam qualquer forma de cuidado direto ou planejamento que reflita na melhoria da qualidade de vida do usuário ${ }^{(11)}$. O profissional deve estar atento a todo o projeto de intervenção junto ao usuário e próximo de seu contexto familiar, pois quanto mais envolvidos em seu processo cuidativo, o usuário e sua família podem se tornar protagonistas na manutenção da saúde ${ }^{(11)}$. Para tanto, é papel do enfermeiro fomentar o desenvolvimento da sua consciência social, uma vez que o estabelecimento das melhores práticas está diretamente ligado ao potencial de fortalecimento e empoderamento desses grupos, 
oriundos das reproduções sociais que, por sua vez, interferem no desenvolvimento biopsicossocial do indivíduo ${ }^{(11)}$.

Perante essas considerações, emerge a questão de pesquisa: quais são as potencialidades e desafios para o desenvolvimento de melhores práticas de enfermagem, em diferentes contextos assistenciais? Nessa direção, objetivou-se compreender as potencialidades e desafios no desenvolvimento de melhores práticas de enfermagem em um contexto assistencial.

\section{MÉTODOS}

Estudo qualitativo, guiado pelo Itinerário de Pesquisa de Paulo Freire, que se alicerça numa perspectiva pedagógica libertadora, conduzida por meio do diálogo e de relações horizontalizadas.

Considerando o referencial metodológico de Freire ${ }^{(12)}$,o estudou foi organizado em três momentos dialéticos: investigação temática; codificação e descodificação; e desvelamento crítico, organizados por meio de espaços chamados de Círculo de Cultura (CC), os quais se caracterizam por um grupo de pessoas com algum interesse comum, que discutem sobre seus problemas e situações de vida, construindo uma percepção mais profunda sobre a realidade ${ }^{(12-13)}$.

A pesquisa foi realizada em um contexto assistencial composto por três municípios situados na Macrorregião Oeste de Santa Catarina, população total aproximada de $18 \mathrm{mil}$ habitantes, com serviços de atenção primária, secundária e terciária. A escolha desses municípios se justifica por se tratar de um cenário bem definido, com os três níveis assistenciais, mas que, reconhecidamente, carece de estratégias que melhorem seus fluxos e a comunicação entre os enfermeiros que ali atuam.

Participaram da pesquisa 17 enfermeiros, destes 11 eram profissionais em Unidades Básicas de Saúde, três em Centro de Apoio Psicossocial e Pronto Atendimento e três no Hospital, sendo a maioria mulheres (16 participantes). Foi critério para a inclusão, atuar como enfermeiro em um dos serviços daquele contexto há, pelo menos, três meses. Essa opção não interferiu no processo da pesquisa, uma vez que o foco do estudo foram as melhores práticas, as quais se fortalecem com a experiência profissional, independente do tempo de atuação em um mesmo serviço ${ }^{(10)}$. Excluíram-se os enfermeiros que, no período da coleta de dados, estavam de licença ou afastados do serviço por qualquer motivo.

O Itinerário de pesquisa ocorreu por meio de três $\mathrm{CC}$, tendo a participação média de sete enfermeiros em cada encontro, entre os meses de junho e agosto de 2018. Foram realizadas as três etapas do Itinerário (investigação temática; codificação e descodificação; e desvelamento crítico), com intervalo de, aproximadamente, 21 dias entre os encontros. A dinamicidade e flexibilidade dos CC permitiu que fossem realizados com um número reduzido e irregular de participantes, favorecendo a aproximação destes com os pesquisadores. Essa dinamicidade garante o rigor epistemológico, assim como a reflexão profunda da realidade, promovendo a autonomia dos participantes no processo e sua transformação, conforme a literatura orienta ${ }^{(13)}$.

Os CC tiveram a duração de cerca de duas horas e ocorreram em sala de reuniões, previamente agendados. Dialogou-se sobre a temática e os objetivos da pesquisa e foi realizada a apresentação e justificativa de necessidade da assinatura do Termo de Consentimento Livre e Esclarecido, por todos os participantes da pesquisa. Buscou-se criar um ambiente que favorecesse o diálogo entre o grupo, com os presentes dispostos em torno de uma mesa.

No primeiro encontro, trabalhou-se a investigação temática, a partir de quatro questões disparadoras: há quantos anos você atua como enfermeiro? Fez ou está fazendo alguma pós-graduação? Refletindo sobre sua prática diária, o que você aponta como facilidades ou potencialidades? Quais são os desafios relacionados à sua prática? A partir do primeiro CC, foram investigados 59 Temas Geradores (TGs), extraídos do universo vocabular do sujeito, de acordo com seu cotidiano de vida $^{(12)}$.

No segundo encontro, os TGs investigados foram debatidos com o grupo, caracterizando a etapa da codificação e descodificação. Com tarjetas coloridas dispostas em um painel, os participantes identificaram a ordem de prioridade para a sua discussão, a fim de resgatar principais elementos descodificados no próximo CC. Dos TGs identificados na primeira rodada, 16 foram codificados e descodificados, como sendo os mais representativos das principais demandas vivenciadas pelo grupo. No último CC, em um contínuo processo de ação-reflexão-ação sobre a realidade, os participantes desvelaram como 
sendo duas as principais as temáticas que versavam sobre as potencialidades e desafios no desenvolvimento das melhores práticas no contexto da RAS.

O desvelamento dos Temas investigados foi realizado com todos os participantes envolvidos no estudo, como sugere o Método Paulo Freire ${ }^{(12)}$. O Referencial Teórico das melhores práticas, aliado às concepções Freireanas, contribuíram para o processo de desvelamento crítico dos Temas, a partir da análise das informações, que ocorreu, por meio de leitura cuidadosa das informações registradas.

Os Temas destacados nortearam 0 momento para a reflexão entre os participantes, a fim de descodificar os TGs. Atendendo ao referencial teórico-metodológico crítico e participativo, preconizado pelo referencial teórico metodológico, a análise dos dados dos CC ocorreu, concomitantemente, à produção das informações. Desse modo, em todas as etapas da investigação temática, os pesquisadores realizaram a transcrição do material gravado em áudio, organizaram os registros do material produzido. Este foi lido, buscando sistematizar as informações (redução temática) e apresentá-las de modo organizado às participantes no início de cada novo encontro ${ }^{(13)}$.

$\mathrm{O}$ registro dos TGs ocorreu em bloco de notas de uso pessoal da pesquisadora/mediadora, e também em gravação de áudio, mediante consentimento. A pesquisa foi desenvolvida conforme as diretrizes da Resolução no 466/12 do Conselho Nacional de Saúde, para pesquisas envolvendo seres humanos, parecer de aprovação no Comitê de Ética em Pesquisa número 2.380.748, de novembro de 2017, autorizada pela Comissão Intergestores Regional, a qual a RAS está vinculada. Para garantir o anonimato, os participantes foram identificados com nomes de pedras preciosas de acordo com escolha individual.

\section{RESULTADOS E DISCUSSÃO}

A fim de valorizar o Método Freireano como ação educativa e libertadora, os resultados serão apresentados no contexto da sua produção, durante os CC.

\section{Investigação Temática}

No primeiro CC, foi apresentada a pesquisa aos participantes e realizada a investigação dos principais TGs. Buscou-se promover um momento de autorreflexão dos enfermeiros sobre a sua trajetória profissional e sobre a enfermagem, a partir das questões norteadoras. Sobre isso, os participantes referem:

"[...] A gente tem um grande campo [de conhecimento], só que a gente está sempre fazendo o trabalho dos outros. A gente conhece a nossa população, a potencialidade está em trabalhar com eles, justamente por conhecer! Só que [...] a gente acaba fazendo o papel do médico, do psicólogo, de mediador familiar" (Rubi).

Os diálogos que emergiram dos CC denunciam a dificuldade dos enfermeiros para reconhecerem sua identidade profissional, nesse cenário. Estudos, há tempos, indiciam a tendência do enfermeiro em "fazer tudo" ${ }^{\text {(14), }}$ assumindo papéis que seriam de outras categorias profissionais ${ }^{(15)}$. Para Toso e colaboradores $^{(15)}$, o enfermeiro não possui competência, nem amparo legal e, muito menos, - reconhecimento formal da sociedade para desenvolver práticas que são atribuições de outros profissionais, com o mesmo significado que elas adquirem em países, nos quais se desenvolve a Enfermagem de Prática Avançada(EPA) ou a Prática Baseada em Evidências, por exemplo. Assim, é preciso investir em pesquisas que diagnostiquem as práticas desenvolvidas e aquelas que são possíveis, no contexto brasileiro.

\section{Codificação e Decodificação}

No segundo $\mathrm{CC}$, uma dinâmica com tarjetas coloridas em painel para visualização desencadeou a discussão coletiva e posterior codificação e descodificação dos TGs, resultando assim, nos 16 TGs finais.

A codificação e descodificados pelo grupo, culminou em 16 Temas de interesse, separados pelo grupo, durante os CC, em duas dimensões(D): D1) potencialidades e D2) desafios frente ao desenvolvimento das melhores práticas de enfermagem na RAS. 
Figura 1 - Apresentação das dimensões (D1 e D2) e dos 16 TGs emergidos dos CC.

\begin{tabular}{|c|c|}
\hline $\begin{array}{l}\text { D1) Potencialidades para melhores } \\
\text { práticas de enfermagem na RAS }\end{array}$ & $\begin{array}{c}\text { D2) Desafios para melhores } \\
\text { práticas de enfermagem na RAS }\end{array}$ \\
\hline $\begin{array}{c}\text { Trabalho em equipe } \\
\text { Liderança } \\
\text { Vínculo com o paciente } \\
\text { Espaços de aprendizagem coletiva } \\
\text { Empoderamento do enfermeiro }\end{array}$ & $\begin{array}{c}\text { Equipe reduzida } \\
\text { Burocratização do trabalho } \\
\text { Falta reconhecimento profissional } \\
\text { Remuneração baixa } \\
\text { Falta de diálogo entre enfermeiros e com equipe multi } \\
\text { Ausência de Educação Permanente em Saúde (EPS) } \\
\text { Falta de autonomia } \\
\text { Pouco apoio (da gestão) } \\
\text { Interferência política na assistência } \\
\text { Sobrecarga de trabalho } \\
\text { Falta de valorização e cuidado com cuidador }\end{array}$ \\
\hline
\end{tabular}

Fonte: dados da pesquisa, 2018.

Observou-se, nessa etapa, que o diálogo destacou-se como ferramenta essencial na construção das reflexões coletivas. A dinâmica inicial disparou a problematização da temática central do estudo e proporcionou um momento rico de troca de vivências, desabafos, insatisfações e também alegrias vivenciadas na prática e no processo de trabalho dos enfermeiros.

Nas fases da codificação e descodificação dos TGs, as situações, anteriormente apreendidas aleatoriamente, ganharam significado mediante a possibilidade de diálogo e a "visão mágica" foi substituída por uma "visão crítica", fazendo com que os participantes se percebessem como protagonistas, com potencial para transformar a realidade ${ }^{(13)}$. Dispostos em círculo, externaram suas percepções críticas, por exemplo, em relação à falta de cuidado com o cuidador:

"[...] A gente oferece um cuidado melhor para eles [usuários] e não oferecem cuidado nenhum para nós (profissionais)" (Rubi).

As falas remetem à insatisfação com a profissão, sobretudo pelo acúmulo de atividades designadas ao enfermeiro que, por sua formação generalista, é reconhecido pela equipe como o profissional habilitado para resolver problemas de todas as ordens:

“[...] Isso é um pouco de todos, a gente não se detém nas funções do enfermeiro [...] ajudando a resolver tantas outras coisas que deixa a assistência mais efetiva e mais presente do paciente em segundo plano" (Ametista).

No decorrer dos encontros, houve maior aproximação com o tema "melhores práticas de enfermagem", a tomada de consciência sobre o trabalho e os fluxos de comunicação em um contexto assistencial específico, considerando os serviços disponíveis e a importância de se alcançar a autonomia profissional, inclusive, com vistas ao cuidado com o cuidador. Os desafios da enfermagem para o desenvolvimento das suas práticas implicam, principalmente, o contexto de trabalho. Fica perceptível, de forma, inclusive, coerente com outros estudos, que as relações de poder que se estabelecem em determinados cenários de práticas nos quais atuam diferentes profissionais, carecem de alteridade por parte destes e transformações no usuário e no trabalhador, de modo que o cuidado seja menos protocolar, normatizado, abrindo-se para possibilidades mais criativas e relações mais fecundas, a partir dos encontros que ali se estabelecem ${ }^{(16-17)}$.

Percebem-se diversas situações limite ${ }^{(13)}$ pontuadas pelos enfermeiros, comuns aos diferentes contextos de atuação, especialmente, aqueles relacionados à gestão dos serviços. Outro ponto em destaque remete à burocratização do trabalho e à cobrança do gestor pela agilidade e produção, somados à falta de pessoal, como ilustra a fala:

"A estrutura da APS foi mudando, foram acrescentando funções, programas, [...] o quantitativo de pessoal ou equipe mínima, que consta na política, continua o mesmo. E a gestão não quer saber se aumentou ou não o serviço, eles cumprem com o mínimo. Para fazer um preventivo [exame preventivo de Câncer de Colo Uterino], por exemplo, você precisa digitar em três sistemas diferentes a mesma informação. Isso demanda tempo" (Safira).

Os participantes destacam como desafios para sua atuação a falta de reconhecimento do enfermeiro e do seu papel pelos gestores e usuários, os baixos salários, a sobrecarga de trabalho, a falta de diálogo entre os enfermeiros dos diferentes níveis assistenciais e com as 
equipes multiprofissionais que atuam na $A P S / A B$, a falta de autonomia e de apoio (respaldo), da gestão e do próprio Ministério da Saúde, para realizar determinados procedimentos e condutas:

"[...] a falta de autonomia em alguns procedimentos, que é relacionada a você estar fazendo determinadas ações e não ter, por questões éticas, respaldo; outras situações de falta de respaldo por parte do Ministério, muitas vezes você sofre boicotes e, mesmo você conseguindo construir tudo isso, ou através do prestador, você construindo isso dentro do município, se você tiver que fazer um encaminhamento, exames de imagem, esse tipo de coisa que hoje teria aval, você também sofre" (Diamante).

Com relação à temática da falta de autonomia, refletiu-se sobre a construção social da profissão no Brasil e no mundo, a partir de um resgate histórico. $O$ grupo relatou que, de maneira geral, as ações da enfermagem permanecem no anonimato, fazendo com que a profissão tenha pouca visibilidade, à deriva de outras:

"A gente tem essa potencialidade, mas ao mesmo tempo está estagnado, não está buscando se unir, se fortalecer para melhorar isso" (Ônix).

“[...] a gente está escondida atrás da parte médica. Porque, na verdade, a nossa cultura é fogo! Na cabeça das pessoas, daqueles que dependem [do cuidado - usuários], a enfermeira ou o papel da enfermeira é simplesmente trocar fralda, ajudar a levar no banheiro, poucos enxergam realmente a importância" (Ametista).

Nesse sentido, emerge a necessidade de desenvolvimento da liderança do profissional de enfermagem $^{(18)}$ e, no âmago dessa proposta de transformação do modelo vigente, nasce o apoio matricial, a partir de experiências institucionais voltadas para transformar o cotidiano. $O$ apoio matricial consiste na distribuição de poder entre profissionais e equipes e em relações pactuadas na alteridade e mediação de $\operatorname{conflitos}^{(17)}$. No Canadá, Espanha e Portugal, alguns serviços operam na perspectiva do apoio, a partir do conceito de "Enfermeiro de Ligação ou de Enlace", com o propósito de estabelecer comunicação com o paciente e assegurar a continuidade do cuidado entre o hospital e outros serviços. Essa função corresponde ao profissional que realiza a articulação nas Redes de Assistência à Saúde (referência do usuário entre os pontos de atenção, na lógica da clínica ampliada) ${ }^{(19)}$. Cabe questionar se a figura do gerente, emergida na Política Nacional de Atenção Básica $(P N A B)^{(20)}$ que orienta a APS no Brasil, deve abarcar essas atribuições e/ou se tais atividades poderiam evoluir para outras expressões - como a EPA ou a Enfermeira de Apoio, objetivando-se, assim, aproximar os serviços e o fluxo de informações. Nessa direção, a troca de saberes entre os profissionais seria uma linha de comunicação integrativa, colaborando com a consolidação dos conhecimentos e com a coordenação do cuidado na APS $^{(16,19)}$.

No entanto, ficou claro que os enfermeiros estavam pouco familiarizados com a expressão "melhores práticas". À medida que a pesquisadora foi trazendo alguns conceitos, as falas foram emergindo:

"Talvez seja aquela prática que você ocupa menos material [...] leva em consideração o custo-benefício do procedimento" (Safira).

Nesse ponto, houve divergências de opiniões sobre o conceito, contudo, todos entendem que, para ser considerada uma "melhor prática", é preciso considerar o contexto e a cultura do paciente, os recursos disponíveis e a experiência profissional:

"Outro fator importante é a questão da negociação, sempre! É assim que se trabalha, nunca você vai chegar e cortar as coisas de alguém, ou falar: a senhora tem que guardar a comida na geladeira, mas talvez ela não tenha uma geladeira em casa né? Então é partir da realidade de cada um" (Ametista).

Atrelado ao conceito de melhores práticas estão os atributos essenciais da APS, como o acesso, a resolutividade e a integralidade, além das relações de afeto e vínculo entre profissionais, usuários e com a própria gestão dos serviços, atendendo aos atributos coordenação do cuidado e à competência cultural ${ }^{(20)}$. Esses elementos estão subentendidos nas falas dos enfermeiros, quando destacam que, tanto as potencialidades quanto as fragilidades que implicam o desenvolvimento de práticas de cuidado de enfermagem, nos contextos assistenciais, têm a ver com questões de vínculo e afeto, com usuários e com os membros da equipe multiprofissional e, mesmo, com as relações de poder que ali se estabelecem ${ }^{(16)}$.

A PNAB preconiza que o processo de trabalho em saúde propicie relações de vínculo, responsabilização entre as equipes e a população adstrita, garantindo a continuidade das ações e a 
longitudinalidade do cuidado ${ }^{(20)}$. O vínculo com o usuário e comunidade direciona a uma relação de confiança, assim como a liderança e o fato de o enfermeiro ser considerado o profissional de referência para a equipe e também para $o$ usuário:

"Uma potencialidade [...] é o vínculo que a gente tem com a população" (Ágata).

"Na interação com os pacientes você tem uma facilidade bem grande nessa profissão, com a equipe também. Gerenciar problemas; você acaba por realizar questões administrativas, questões técnicas, questões de área e problemas clínicos, médicos, você acaba sendo o (profissional) mais qualificado" (Diamante).

Em estudo sobe o tema ${ }^{(22)}$, identificou-se que, além dos prejuízos pessoais ao profissional, esses fatores afetam, diretamente, a qualidade do cuidado, situação agravada pela estrutura física e organizacional inadequada, falta de materiais, de equipamentos e de pessoal. Acrescenta-se a isso, a falta de reconhecimento e de autonomia percebida pelos enfermeiros, ao atuar, nesse contexto, além da baixa remuneração, reflexos da construção social da profissão. A reversão desse quadro só será possível com o empoderamento do profissional e seu engajamento nas lutas por melhorias para a categoria, construção da identidade profissional e fundamentação da prática em seu pilar essencial: o cuidado de enfermagem ${ }^{(18)}$.

Percebeu-se a clareza do papel da enfermagem para viabilizar os pressupostos contidos na PNAB, apesar dos desafios da prática profissional. Todavia, ao desvelá-los, os enfermeiros relataram vivenciar situações de sofrimento moral, desencadeadas pela sobrecarga de trabalho, falta de humanização e valorização, além da hegemonia de uma gestão pouco colaborativa, levando à insatisfação com o trabalho e, por vezes, com a profissão ${ }^{(19)}$. Destacaram a falta de diálogo na atuação em rede e sinalizaram a possibilidade de espaços dialógicos e de compartilhamento de vivências, que podem auxiliar na busca por estratégias conciliadoras e resolutivas, face aos problemas de comunicação enfrentados no cotidiano ${ }^{(23)}$.

"[...] Todos [os profissionais], absolutamente todos, tem que falar a mesma linguagem" (Esmeralda).

"Ele [usuário] vai para algum especialista, vai para outro médico, daí ele volta de novo [...] A gente consegue ver o todo, na $A B$ a gente vê o todo, ele inserido na sociedade, ele inserido na família, toda essa estrutura externa" (Jade).

A temática da falta de diálogo foi considerada um nó crítico para a prática dos enfermeiros, que afeta negativamente a assistência, principalmente, quanto à longitudinalidade do cuidado. Foi problematizada a importância do vínculo e o acompanhamento do indivíduo em longo prazo, atendendo à coordenação do cuidado e à competência cultural $^{(20)}$ :

“[...] Eles [usuários com sofrimento psíquico] entram em surto, acabam indo parar no hospital. Agora, desses que mais surtam ou que são de difícil adesão ao tratamento, eu seguro as receitas aqui, principalmente do haldol [medicamento]. Se o paciente não vem no dia, eu sei que ele tem que fazer, e aí eu acabo fazendo busca ativa desse paciente para administrar a medicação" (Safira).

\section{Desvelamento Crítico}

A fase do desvelamento crítico ocorreu no último CC. Esta "retrata a reflexão preliminar das propostas extraídas, por meio da codificação objetiva, abarcando princípios da subjetividade interpretativa. Retrata a realidade e as possibilidades $^{\prime(13)}$. Entre as potencialidades e desafios, as temáticas reduzidas e reapresentadas no CC foram evidenciadas pelos presentes, destacando-se aquelas intrínsecas à profissão: necessidade de autonomia, de reconhecimento, a insatisfação com o emprego, baixos salários; e temáticas relacionadas a atuação em equipe: gestão colaborativa e diálogo entre enfermeiros. Nesse momento, estimulou-se a reflexão (e ação) dos participantes, buscando a problematização e a passagem da consciência ingênua para a consciência crítica, bem como a descoberta das situações limite ${ }^{(13)}$. A elucidação do conceito de melhores práticas estimulou esse processo. Nessa direção emergiram falas, como:

"Eu trabalho na saúde mental e penso que uma boa prática foi trazer os familiares ou um acompanhante na consulta do paciente. Porque caso contrário, o paciente vinha e saía da consulta e não sabia o que fazer com a receita que o médico deu, com a orientação" (Safira).

A oportunidade de participar dos CC favoreceu a construção de novas possibilidades de transformação das práticas do cotidiano, exemplificada por falas como a seguinte, que destaca a importância do diálogo entre 
enfermeiros que atuam nos diferentes pontos da Rede:

"Eu não imaginei que seria tão bom um momento desses! O simples fato de estarmos reunidos já é um acontecimento histórico. Poder trocar ideias, falar de problemas gerais, até nos dá um certo alívio" (Ametista).

"Eu acho muito bons esses encontros, a gente sempre queria ficar mais um pouco, trocar experiências, conhecer a realidade do outro, e até nos divertimos" (Cristal).

A identificação das potencialidades, embora tímida, emergiu nas reflexões instigadas pela pesquisadora, durante os diálogos dos CC. O amor pela profissão, o cuidado com o bem-estar do paciente, o potencial da liderança e destaque na equipe e no serviço, são algumas. Nesse sentido, autores ${ }^{(18)}$ destacam a importância de valorizar a formação de líderes na enfermagem, pois isso corrobora para a conquista do apoio da equipe, encorajando-a e criando condições para enfrentamento de situações adversas. Em última instância, também favorece o olhar clínico do enfermeiro e, por conseguinte, a melhora da assistência prestada.

Em relação à estruturação de espaços dialógicos nos serviços, é preciso haver interesse e vontade dos envolvidos, tanto dos trabalhadores, dos usuários, quanto dos gestores. A articulação e a comunicação entre os enfermeiros são estratégias implementadas para que se estabeleçam esses fluxos. Além disso, o empoderamento do enfermeiro e a qualificação das suas práticas, por meio da produção e consumo do conhecimento científico, respalda sua tomada de decisão e eleva seu potencial argumentativo, numa posição de horizontalidade ante outras profissões ${ }^{(11)}$.

"[...] Quanto melhor o teu conhecimento, melhor é a tua prática" (Ônix).

O encerramento dos encontros ocorreu de forma descontraída, evidenciando a aproximação entre todos os participantes, favorecida pelo contexto da pesquisa e o método utilizado. Os enfermeiros manifestaram a necessidade de momentos como os proporcionados pelos CC, de aprendizagem coletiva e trocas de vivências, para que os serviços daquele contexto assistencial operem de forma efetiva e para a melhoria da sua prática:

"[...] Refletir sobre o que fazemos e onde queremos chegar. Muito válido, até para conhecer a realidade da $A B$, que a gente que está no outro ponto as vezes julga, não entende, não sabe o que acontece" (Cristal).

Ao problematizar questões oriundas do processo laboral, foi possível compartilhar objetivos, desenvolver identidade de equipe e buscar o cuidado integral, considerando o caráter complexo e dinâmico das necessidades de saúde ${ }^{(24)}$. Fica claro que o sucesso do trabalho em equipe, na enfermagem, depende da relação que se estabelece entre os profissionais e que existem elementos que podem implicá-las, tais como a formação, a experiência profissional e dinâmicas de trabalho. Convém destacar também, nesse contexto, a atenção para o fato de que a Prática Avançada é possível, por meio de uma formação, de um campo de especialização, quer seja na parte clínica do cuidado, quer seja na promoção e prevenção ${ }^{(15)}$.

O CC, enquanto espaço dialógico, possibilitou a descodificação sobre as potencialidades e desafios no desenvolvimento das melhores práticas. As participantes refletiram sobre os TGs á luz desse conceito e, durante o processo, se reconheceram capazes de transformar a realidade ${ }^{(13)}$. Inicialmente, refletiram sobre o papel do enfermeiro na equipe e para o serviço. A tomada de consciência sobre sua trajetória desvelou possibilidades de mudanças e soluções passíveis de serem implementadas e que antes, não eram percebidas. Os enfermeiros entendem que, para que melhores práticas aconteçam nos serviços de saúde, estes precisam prover condições para que o profissional esteja em constante atualização científica e que isso seja parte de sua rotina de trabalho, tanto quanto as atividades de cuidado $^{(12)}$.

Finalmente, os Círculos promoveram articulação da produção do conhecimento e aprendizado significativo em serviço ${ }^{(25)}$. Para além de processos de educação, configuraram-se como movimentos dialógicos e de intercâmbio de saberes, desencadeados pelos encontros e interações concretas entre os sujeitos, com aplicabilidade pedagógica no território em que a vida acontece ${ }^{(24-25)}$.

\section{CONSIDERAÇÕES FINAIS}

Os TGs identificados e problematizados pelos participantes demonstram um longo caminho a percorrer, naquele contexto assistencial, cujo primeiro passo foi a possibilidade do encontro entre os enfermeiros dos diferentes níveis e serviços. Faz-se necessário 
estabelecer elos de comunicação duradouros entre eles, permeados pelo diálogo e espaços de aprendizagem coletivos, que despertem a avidez pela busca e compartilhamento do saber.

O cuidado que se pretende no campo da produção de saúde, no contexto estudado, aponta para a possibilidade de práticas de enfermagem que se aprimorem a partir da busca pelo conhecimento e que impliquem relações entre os sujeitos, abrindo-se para diferentes modos de ver, ouvir, pensar, sentir e cuidar.

Destaca-se a potencialidade da metodologia do CC, para o desenvolvimento da pesquisa em saúde, proporcionando momentos de diálogo e reflexão. Entendida como metodologia crítico-reflexiva, permite a açãoreflexão-ação, tornando o pesquisador um mediador e um participante do estudo.

Como limitações, deste estudo, identificamos a realização em um contexto representado, por somente três municípios, com número mínimo de profissionais de enfermagem. Considera-se, ainda, a temporalidade do estudo como uma limitação, uma vez que a APS tem passado por transformações importantes, com precoce implantação da PNAB. Sendo assim, sugere-se $O$ desenvolvimento de outras pesquisas, ampliando cenários e difundindo o conceito e relevância das melhores práticas de enfermagem.

\section{REFERÊNCIAS}

1. Morosini MVGC, Fonseca AF. Revisão da Política Nacional de Atenção Básica numa hora dessas? Cad Saúde Pública 2017;33(1):e00206316. DOI: 10.1590/0102$311 \times 00206316$

2. Mendes EV. A construção social da Atenção Primária à Saúde. Brasília: Conselho Nacional de Secretários de Saúde; 2015.

3. Moll MF, Goulart MB, Caprio AP, Ventura CAA, Ogoshi AACM. O conhecimento dos enfermeiros acerca as redes de atenção à saúde. Rev Enferm UFPE 2017;11(1):86-93. DOI: 10.5205/reuol.9978-88449-6-1101201711

4. Almeida JHH, Feitosa ANA, Araújo WA, Silva JB, Lourenço LC, Sousa MNA. Primary health care: Focusing on the health for the attention of networks. J Nurs UFPE 2015;9(11):9811-16. DOI: 10.5205/reuol.8008-72925-1-ED.0911201522

5. Maffissoni A, Vendruscolo C, Trindade LL, Zocche DA. Redes de atenção à saúde na formação em enfermagem: Interpretações a partir da atenção primária à saúde. Rev Cuid. 2018;9(3):1-13. DOI: 10.15649/cuidarte.v9i3.549

6. Laurant $M$, Van der Biezen $M$, Wijers $N$, Watananirun K, Kontopantelis E, Van Vught AJAH. Nurses as substitutes for doctors in primary care. Cochrane Database Syst Rev 2018(7):CD001271. DOI: 10.1002/14651858.CD001271.pub3

7. Mackey A, Bassendowski S. The history of evidence-based practice in nursing education and practice. J Prof Nurs. 2017;33(1):51-5. DOI: 10.1016/j.profnurs.2016.05.009

8. Barbiani R, Nora CRD, Schaefer R. Nursing practices in the primary health care context: $A$ scoping review. Rev Latino-Am Enfermagem 2016;24:1-12. DOI: 10.1590/15188345.0880 .2721

9. Silva FAM, Cassiani SHB, Freire Filho JR. A Educação Interprofissional em saúde na Região das Américas. Rev Latino-Am Enfermagem 2018;26:1-2. DOI: 10.1590/1518-8345.0000.3013 10. Organização Mundial da Saúde (OMS). Guia para a documentação e partilha das melhores práticas em programas de saúde. Genebra: OMS; 2008

11. Egry EY. Um olhar sobre as boas práticas de enfermagem na atenção básica. Rev Bras Enferm 2018; 71(3):930-1. DOI: 10.1590/00347167.2018710301

12. Freire P. Pedagogia do oprimido. 64a ed. Rio de Janeiro: Paz e Terra; 2017.

13. Heidemann ITSB, Dalmolin IS, Rumor PCF, Cypriano CC, Costa MFBNA, Durand MK. Reflexões sobre o itinerário de pesquisa de Paulo Freire: Contribuições para a saúde. Texto Contexto-Enferm. 2017;26(4):1-8. DOI: 10.1590/0104-07072017000680017

14. Fernandes MC, Silva LMS, Silva MRF, Torres RAM, Dias MSA, Moreira TMMM, et al. Identity of primary health care nurses: Perception of "doing everything". Rev Bras Enferm. 2018;71(1):142-7. DOI: 10.1590/0034-7167-20160382

15. Miranda Neto MV, Rewa T, Leonello VM, Oliveira MAC. Advanced practice nursing: A possibility for Primary Health Care? Rev Bras Enferm. 2018;71(Suppl 1):716-21. DOI: 10.1590/0034-7167-2017-0672

16. Andrade EO, Givigi LRP, Abraha?o AL. The ethics of self-care as a way of creating possibles for work in Health. Interface 2018;22(64):6776.DOI: 10.1590/1807-57622016.0643

17. Campos GWS, Figueiredo MD, Pereira Júnior N, Castro CP. Application of Paideia methodology to institutional support, matrix 
support and expanded clinical practice. Interface 2014;18(1):983-95.DOI: $\quad$ 10.1590/180757622013.0324

18. Ferreira VB, Amestoy SC, Silva GTR, Felzemburgh RDM, Santana N, Trindade LL, et al. Liderança transformacional na prática dos enfermeiros em um hospital universitário. Acta Paul Enferm. 2018;31:644-50. DOI: 10.1590/1982-0194201800088

19. Ribas EN, Bernardino E, Larocca LM, Poli Neto P, Aued GK, Silva CPC. Nurse liaison: A strategy for counter-referral. Rev Bras Enferm. 2018;71(1):546-53. DOI: 10.1590/0034-71672017-0490

20. Brasil, Ministério da Saúde. Portaria no 2.436, de 21 de setembro de 2017. Aprova a Política Nacional de Atenção Básica, estabelecendo a revisão de diretrizes para a organização da Atenção Básica, no âmbito do Sistema Único de Saúde. Diário Oficial da União 2017.

21. Starfield B. Atenção primária: Equilíbrio entre necessidades de saúde, serviços e tecnologia. Brasília: UNESCO; 2002.

22. Ramos FR, Barth PO, Schneider AMM, Cabral AS, Reinaldo JS. Consequências do sofrimento moral em enfermeiros: Revisão integrativa. Cogitare Enferm. 2016;21(2):1-13. DOI: $10.5380 / c e . v 21 i 2.45247$

23. Medeiros ABA, Enders BC, Lira ALBC. Teoria ambientalista de Florence Nightingale: Uma análise crítica. Esc Anna Nery 2015;19(3):518-24. DOI: 10.5935/14148145.20150069

24. Vendruscolo C, Ferraz F, Prado ML, Kleba ME, Martini JG. Instâncias intersetoriais de gestão: Movimentos para a reorientação da formação na saúde. Interface 2018;22(1):135364. DOI: 10.1590/1807-57622017.0180

25. Ferreira L, Barbosa JSA, Esposti CDD, Cruz MM. Permanent Health Education in primary care: An integrative review of literature. Saúde Debate 2019;43(120):223-39. DOI: 10.1590/01031104201912017

Note: Artigo resultante de pesquisa de dissertação.

Recebido em: 30/06/2019

Aprovado em: 18/11/2019

Endereço de correspondência:

Mônica Ludwig Weber

Rua Osvaldo Cruz, 56 - Centro

CEP: 89885-020 - São Carlos/SC- Brasil

E-mail: monyludwig@hotmail.com 